\title{
PREPARATION OF ANTIBACTERIAL IRON-BASED NANOPARTICLES USING Ruellia tuberosa L. ROOT EXTRACTS AS BIOREDUCTOR
}

\author{
A. Safitri ${ }^{1,2, *}$, M. Ramadhan ${ }^{1}$, and A. Sabarudin ${ }^{1,3}$ \\ ${ }^{1}$ Chemistry Department, Brawijaya University, Malang, 65145, Indonesia \\ ${ }^{2}$ Research Center for Smart Molecules of Natural Genetic Resources (SMONAGENES), \\ Brawijaya University, Malang, 65145, Indonesia \\ ${ }^{3}$ Research Center for Advanced System and Material Technology, Brawijaya University, \\ Malang, 65145, Indonesia \\ *E-mail: a.safitri@ub.ac.id
}

\begin{abstract}
In the current work, iron nanoparticles (Fe-NPs) were prepared from extracts of Ruellia tuberosa L. extracted with ethanol and water, and their antibacterial activities toward pathogenic bacteria ( $S$. aureus and E. coli) were investigated. The morphologies, structures, sizes and distribution of atom on the surface of Fe-NPs were checked by SEM-EDS, UV-Vis and FTIR spectroscopy. The $\mathrm{pH}$ conditions $(3,5,7$, and 9) were chosen as experimental factors for the preparation of Fe-NPs. Formation of results in mostly spherical shapes with particle size found within the range $15-50 \mathrm{~nm}$, and the smallest particle size was obtained from $\mathrm{pH}$ 9. UV-Vis spectra confirmed that the formation of Fe-NPs emerged in the UV region around $275 \mathrm{~nm}$. FTIR spectra showed the presence of polyphenolic compounds from extracts of $R$. tuberosa $\mathrm{L}$, that decreasing aggregations of Fe-NPs and act as bioreductors. As Fe(II) reduced to $\mathrm{Fe}(0)$, oxidation of $-\mathrm{O},-\mathrm{OH}$, and $-\mathrm{CHO},-\mathrm{COOH}$ occurred. The optimal condition for antibacterial activities was at $\mathrm{pH} \mathrm{3,} \mathrm{resulted} \mathrm{in} \mathrm{the} 16.70$ and $13.40 \mathrm{~mm}$ of inhibition zones, for $S$. aureus and E. coli, respectively.

Keywords: Iron Nanoparticles, Antibacterial Agent, Ruellia tuberosa L., SEM-EDS
\end{abstract}

(C) RASĀYAN. All rights reserved

\section{INTRODUCTION}

Iron nanoparticles (Fe-NPs) can be easily prepared by different techniques, both chemically and physically. For instance, salts of $\mathrm{Fe}(\mathrm{II})$ or $\mathrm{Fe}(\mathrm{III})$ reacted with $\mathrm{NaBH}_{4}$ as reducing agents, vacuum sputtering, and the use of organic solvents as iron precursors. ${ }^{1,2}$ Chemicals and physical methods have been applied to produce nanoparticles with certain sizes and morphology. However, these techniques involve toxic, corrosive, and flammable compounds, i.e. $\mathrm{NaBH}_{4}$ or organic solvents. ${ }^{2}$ The reactivity and stability of nanoparticles using these methods are usually reduced due to agglomeration of the product. ${ }^{3}$ Therefore, biosynthesis of iron nanoparticles using natural product extracts has appeared as an unpretentious, inexpensive, and eco-friendly approach these days. ${ }^{4,5}$ Biological synthesis of nanoparticles can be carried out with green reagents, microorganisms, and plant biomaterials. Plants can reduce metal ions on their several parts such as leaves, roots, and tissues. ${ }^{6-8}$ Several secondary metabolites are playing a role in nanoparticle formation such as flavonoids, terpenoids, and polyphenols. ${ }^{5-8}$ They are accountable for the size and morphology of the nanoparticles formed..$^{5-8}$

Using plant extracts making nanoparticles is a much simpler, scalable and less expensive method compared to other biological methods. They are responsible for both reducing and stabilizing activities. Several published studies have shown that extracts of the plants can be used to replace chemicals used and physical approaches for the preparation of iron nanoparticles. ${ }^{5-9}$ Organic functional groups such as amines, carboxylic acids and phenols can reduce Fe(II) or Fe(III) in aqueous solution. Recently, plant extracts, such as tea (oolong, green, and black tea), ${ }^{5-7}$ extracts of strawberry, grape, and Euphorbia cochinchinensis leaves, pomegranates, oaks, ${ }^{7}$ and eucalyptus leaf extracts ${ }^{8}$ have been effectively used to synthesize iron nanoparticles.

Rasayan J. Chem., 13(1), 610-620(2020)

http://dx.doi.org/10.31788/RJC.2020.1315511

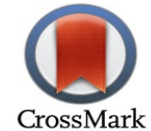




\section{RASĀYAN J. Chem. \\ Vol. 13 | No. 1 |610 - 620| January - March | 2020}

Most studies focus on the whole or parts of plants for the preparation of metal nanoparticles and their applications for numerous purposes. ${ }^{9-11}$ Ruellia tuberosa Linn., a flowering plant species in the Acanthaceae family, locally known as pletekan, can be used in iron nanoparticle synthesis. This plant is widely grown in Indonesia, and also in other South East Asia countries. ${ }^{12} R$. tuberos $a$ L. has been used as an anti-inflammatory, ${ }^{13}$ anti-oxidants, ${ }^{14}$ antibacterial, ${ }^{15}$ and anticancer. ${ }^{16}$ The phytochemical and LC-MS studies revealed that hydroethanolic extracts from $R$. tuberosa L. mostly contained flavonoids and phytosterols. ${ }^{14,15}$

The synthesis of Fe-NPs through the Fe(II/III) bioreduction process using $R$. tuberosa $\mathrm{L}$. root extracts has not been previously reported. This is for the first time that $R$. tuberosa $\mathrm{L}$. extracts are used for the synthesis of nanoparticles. Therefore, it is important to synthesize Fe-NPs using root extracts of $R$. tuberosa L. in a simple step, with the use of non-toxic chemicals and environmentally friendly. Furthermore, in vitro biological activities of the resulted Fe-NPs are investigated through the determination of their biological activity against $S$. aureus and E. coli by the good diffusion method. For the positive control, the antibacterial activity of commercially available antibiotics, chloramphenicol and ampicillin are also tested.

\section{Materials}

\section{EXPERIMENTAL}

The main material used in this research was $R$. tuberosa $\mathrm{L}$. roots powder that acquired from UPT Materia Medica (Batu, East Java). The species determination, Ruellia tuberosa Linn, has been conducted by a botanist from the Materia Medica. All additional chemicals were ethyl alcohol (pure, $d=0.789 \mathrm{~g} / \mathrm{mL}$ ), $\mathrm{FeCl}_{2} \cdot 4 \mathrm{H}_{2} \mathrm{O}\left(\geq 99.0 \%\right.$, analytical grade), ammonium buffer solution $\left(\mathrm{pH} 10-11, \mathrm{~d}=0.978 \mathrm{~g} / \mathrm{cm}^{3}\right), \mathrm{NaOH}$ ( $\geq 97.0 \%$, pellets, analytical grade), and $\mathrm{HCl}(37 \%$, analytical grade), purchased from Sigma-Aldrich, demineralized water (Hydrobatt), nutrient broth (NB) and nutrient agar (NA) were purchased from Merck. Cultures of Staphylococcus aureus (Gram-positive) and Escherichia coli (Gram-negative) were acquired from the Department of Microbiology, State University of Malang. Chloramphenicol and ampicillin (meets USP testing specifications) as a positive control for antimicrobial assay were obtained from Merck.

\section{Instrumentation}

The synthesized Fe-NPs were characterized by UV-Vis (Shimadzu UV-1601 UV-VIS spectrometer), FTIR spectrophotometer (sample was analyzed using a KBr plate, Shimadzu FTIR 8400S) in the wavenumbers of $4000-400 \mathrm{~cm}^{-1}$ and Scanning Electron Microscopy (SEM) (FEI, Type: Inspect-S50).

\section{Preparation of $\boldsymbol{R}$. tuberosa $\mathrm{L}$. Root Extracts}

Distilled water and ethyl alcohol in 1:1 were used to extract $1 \mathrm{~kg}$ of $R$. tuberosa L. root powder (size of approximately $90 \mathrm{mesh}$ ) in the room temperature for $72 \mathrm{~h}$. The extracts were separated through filtration, a rotary evaporator vacuum was used to further concentrated extracts at a low speed at $120 \mathrm{rpm}$, with a temperature of $50{ }^{\circ} \mathrm{C}$. The concentrated extracts were kept at $4{ }^{\circ} \mathrm{C}$ for subsequent use.

\section{Preparation of Fe-NPs}

To prepare Fe-NPs, the concentration ratio applied for $0.1 \mathrm{M} \mathrm{FeCl}_{2}$ aqueous solution and $R$. tuberosa $\mathrm{L}$. root extracts were 1:15. Moreover, the synthesis of Fe-NPs also was carried out in the different $\mathrm{pH}$ values at 3, 5, 7 and 9, by addition of $0.1 \mathrm{M} \mathrm{HCl}$ or $0.1 \mathrm{M} \mathrm{NaOH}$. The obtained Fe-NPs were separated by centrifugation for $10 \mathrm{~min}$, at a speed of $10,000 \mathrm{rpm}$, and the resulting precipitates were washed with demineralized water and ethanol several times. Lastly, Fe-NPs were desiccated for $24 \mathrm{~h}$, in the temperature of $80^{\circ} \mathrm{C}$, using an oven, and stored at desiccator for further analysis.

\section{Characterization of Fe-NPs}

The optical properties of Fe-NPs were analyzed by using a UV-Visible spectrophotometer. The surface morphology of the synthesized Fe-NPs was characterized by performing scanning electron microscopy, and energy-dispersive X-ray spectroscopy (EDS) was applied to confirm the purity of the sample. To identify functional groups in the Fe-NPs, a typical Fourier transform infrared spectroscopy was used. 
RASĀYAN J. Chem.

Vol. 13 | No. 1 |610 - 620| January - March | 2020

\section{Antibacterial Assay}

The Fe-NPs antibacterial activity was analyzed using a good diffusion technique using a previously published method. ${ }^{17}$ The antimicrobial assessment of Fe-NPs was conducted by using S. aureus (Grampositive) and $E$. (Gram-negative) test pathogens. Cultures of bacterial were kept in nutrient broth. A sterile cotton bud was used to spread bacterial culture on nutrient agar plates. The wells of $7 \mathrm{~mm}$ diameter dimensions were formed into the agar medium plates with aid of sterile gel puncture, and the samples were added into the well. The positive controls were chloramphenicol and ampicillin, commercially available antibiotics. The incubation of cultures of the bacteria was conducted overnight at $37{ }^{\circ} \mathrm{C}$, in an upright position. The Fe-NPs were used in the different concentrations: $1 \% ; 1.5 \% ; 5 \% ; 10 \% ; 20 \% ; 50 \%$; and $100 \%(\mathrm{v} / \mathrm{v})$. The detail procedures for the determination of antibacterial activity were described in our preceding paper. ${ }^{15}$ After the incubation period, the diameter of zone inhibitions was quantified with a meter ruler (Vernier calliper) around each disk, and the inhibition average value was determined and stated in millimeter.

\section{Characterization of Fe-NPs}

\section{RESULTS AND DISCUSSION}

After addition of root extracts to $0.1 \mathrm{M}$ aqueous $\mathrm{FeCl}_{2}$ solution, the nanoparticles synthesis reaction started, resulted in the color change from yellow solution (Fig.-1b) to blackish solution (Fig.-1c), indicating the formation of Fe-NPs. A previous study has been reported visual color changes in the metal complexes solutions due to the synthesis of metal nanoparticles. ${ }^{18}$ Characterization of metallic nanoparticles due to such surface plasmon resonance (SPR) phenomenon can be analyzed using a UV-Vis spectroscopy technique. ${ }^{19}$ The conduction of electrons interaction on the surfaces of metal nanoparticles with incident photons may lead to a resonance effect in SPR. ${ }^{20}$ The interaction depends on the composition and nature of the dispersion medium, and also the shape and size of the metal nanoparticles. ${ }^{21}$ Accordingly, a characteristic optical absorption spectrum of metallic nanoparticles is shown in the UV-vis region. ${ }^{19}$
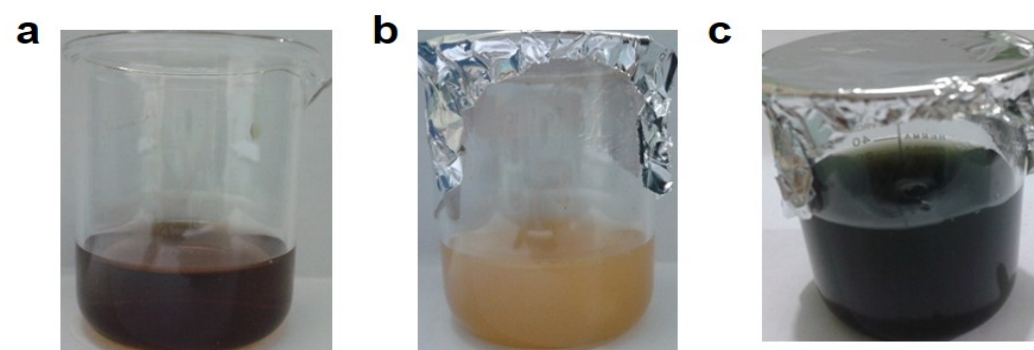

Fig.-1: The Solutions of (a) Hydroethanolic R. tuberosa L. Root Extracts, (b) $\mathrm{FeCl}_{2}$, and (c) Fe-NPs.

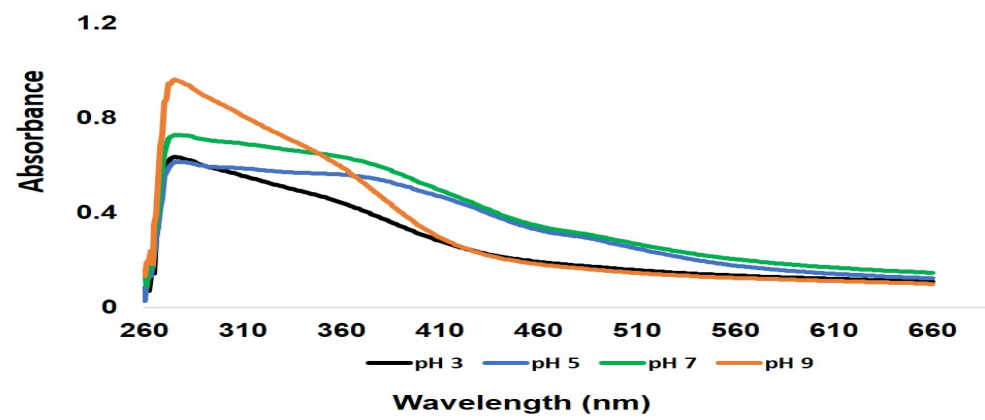

Fig.-2: Results of Fe-NPs From UV-Vis Spectroscopy prepared from $R$. tuberosa L. Root Extracts at Different $\mathrm{pH}$ Conditions.

The absorption peaks were observed around $275 \mathrm{~nm}$ owing to the surface plasmon vibrations excitation in Fe-NPs (Fig.-2). An increase in the sharpness of the absorption peak observed with an increase in the $\mathrm{pH}$ of roots extract. The absorption peaks were larger and also shifted to some extent toward the long- 
RASĀYAN J. Chem.

Vol. 13 | No. 1 |610 - 620| January - March | 2020

wavelength region. An earlier study ${ }^{5}$ showed similar results that the synthesized iron nanoparticles using tea extract showed an absorption peak around $275 \mathrm{~nm}$, showing the formation of iron nanoparticles. The maximum absorption peak in this study was found at the highest $\mathrm{pH}, \mathrm{pH}$ 9. This is consistent with research conducted by Saif et. al. ${ }^{22}$, that the optimum condition of formation of Fe-NPs was achieved at alkaline $\mathrm{pH}$.

Samples of the Fe-NPs were examined by SEM coupled with EDS, to confirm the results of the UV-vis spectral results. The SEM image of Fe-NPs synthesized using root extract of $R$. tuberosa L. is displayed in Fig.-3, together with particle size distribution. As shown in Fig.-3a, the morphology of Fe-NPs formed in $\mathrm{pH} 3$ was rough and uneven, with some irregular and large spherical shapes. These mean that the aggregation of Fe-NPs had occurred and this $\mathrm{pH}$ condition was not optimal for the formation of Fe-NPs. As $\mathrm{pH}$ increases, Fe-NPs show more uniform shapes, and there are decreases in particle sizes of the synthesized metal nanoparticles (Fig. $-3 \mathrm{~b}$ to $3 \mathrm{~d}$ ). At $\mathrm{pH} \mathrm{3,} \mathrm{Fe-NPs} \mathrm{have} \mathrm{average} \mathrm{particle} \mathrm{sizes} \mathrm{of} 10 \mathrm{~nm}$, and size distribution between 5 and $29 \mathrm{~nm}$. In the higher $\mathrm{pH}$ values, $\mathrm{pH} 5$ to $\mathrm{pH} \mathrm{9,} \mathrm{Fe-NPs} \mathrm{have} \mathrm{smaller}$ average particle sizes of 5 to $12 \mathrm{~nm}$, and lower size distribution of 5-23 nm.

Many studies of the metal nanoparticles biosynthesis with plants extract have been reported..$^{9-11}$ The effect of the $\mathrm{pH}$ in the formation of Fe-NPs has been associated with the phytochemical contents within $R$. tuberosa L. root extracts. Our previous study indicated that hydroethanolic roots extract from $R$. tuberosa L. positive contained phenolic compounds, importantly flavonoids and phytosterols. ${ }^{14,15}$ The compounds in the plant extracts contributed to the reduction of positively charged metal ions to their ground state. This is achieved by donating electrons to the ions with the bio-reductors; as in the case of the Fe(II) to $\mathrm{Fe}(0)$ atoms, and small $\mathrm{Fe}(0)$ particles at the beginning of the reaction. ${ }^{23}$ This is followed by these $\mathrm{Fe}(0)$ atom growing into structures of spherical-like, and these Fe-NPs subsequently merging into a stable structure, with the assistance of bio-capping agents from the plant extracts ${ }^{18}$, as illustrated in Fig.-4.

Reduced metals usually undergo nucleation; this process fast occurs at high $\mathrm{pH}$ since the $-\mathrm{OH}$ ions are abundant, accordingly, the formation of small size particles is more likely. ${ }^{18}$ Moreover, the aggregation can be prevented because the same phytochemicals responsible for starting the formation of the Fe-NPs coated the nanoparticles, supplying electron-rich hydroxyl capping agents onto the particles. ${ }^{18,19}$

Additionally, decreasing in particle sizes and constriction of particle sizes distribution can also be related to the nature of phytochemical compounds (e.g. flavonoid compounds) that deprotonated in alkaline conditions. ${ }^{18}$ Flavonoid compounds are more reactive to interact with Fe-NPs and covering more surfaces of Fe-NPs. Subsequently, the formation of aggregation or large clusters on the surface of Fe-NPs is prevented. On the other hand, in acidic $\mathrm{pH}$ conditions, flavonoid compounds may undergo hydrolysis, hence, becoming less reactive and, as a result, is not optimal in preventing aggregation or cluster formation in Fe-NPs. ${ }^{8}$ As a result, in this current study, the finest formation of Fe-NPs resulted in $\mathrm{pH} 9$.

The synthesis of Fe-NPs prepared from $R$. tuberosa L. root extract was subsequently characterized by EDS method, which provides the supplementary indication for the reduction of $\mathrm{Fe}$ (II) to ground state $\mathrm{Fe}(0)$. The spectrum displays intense iron signal alongside with weak signals that can be risen from X-ray emission from organic molecules like phytosterols or flavonoids bound to the NPs or in the neighborhood of the particles (Fig.-5). In general, EDS signal shows the presence of $\mathrm{Fe}, \mathrm{Na}, \mathrm{O}$ and $\mathrm{Cl}$ signals. The percentage of $\mathrm{Fe}$ atoms is getting higher along with increasing $\mathrm{pH}$ value (Table 1). The $\mathrm{Na}$ and $\mathrm{Cl}$ signals may be originated from $\mathrm{NaOH}$ and $\mathrm{FeCl}_{2}$ precursors used in the preparation of Fe-NPs. The oxygen signals are mostly associated with the polyphenol groups and or/ oxygen-based groups, such as -COO and $-\mathrm{OH}$ in the roots extract of $R$. tuberosa L. Nonetheless, the formation of some iron oxide nanoparticles may also be indicated in the $\mathrm{O}$ signal. ${ }^{23}$

Table-1: The Elemental Distribution of the Fe-NPs at Different pH Conditions

\begin{tabular}{r|c|c|c|c|c}
\hline No & $\mathrm{pH}$ & $\% \mathrm{Fe}$ & $\% \mathrm{Cl}$ & $\% \mathrm{Na}$ & $\% \mathrm{O}$ \\
\hline 1 & 3 & 64.30 & 6.01 & 1.42 & 19.65 \\
\hline 2 & 5 & 71.73 & 1.79 & 1.36 & 33.91 \\
\hline 3 & 7 & 74.34 & 1.18 & - & 25.67 \\
\hline 4 & 9 & 74.41 & 0.59 & - & 23.64 \\
\hline
\end{tabular}


RASĀYAN J. Chem.

Vol. 13 | No. 1 |610 - 620| January - March | 2020
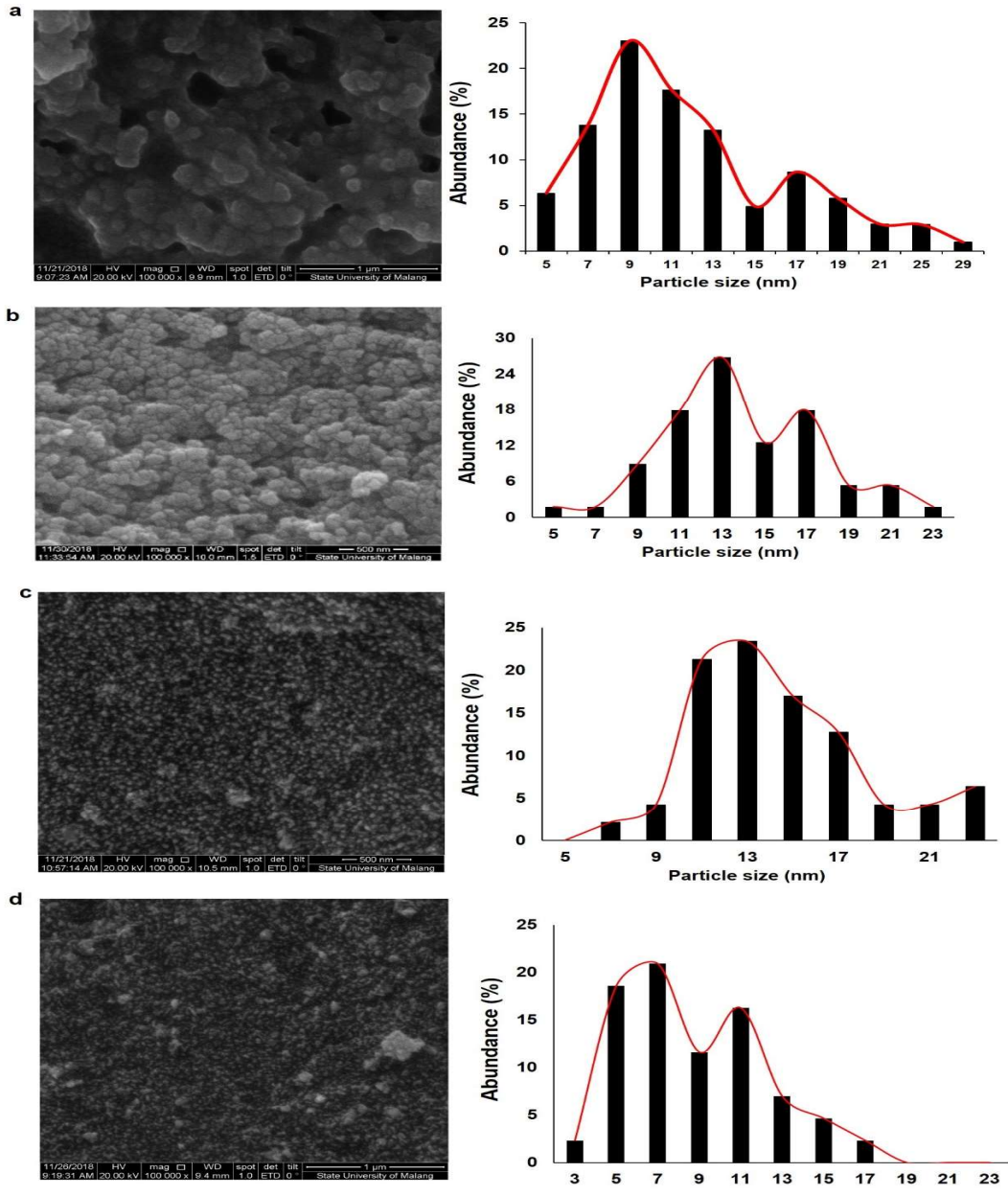

Fig.-3: SEM Images of the Fe-NPs at Various pH Conditions, together with Particle Size Distribution: (a) pH 3; (b) $\mathrm{pH}$ 5; (c) $\mathrm{pH} 7$; and (d) pH 9, Magnification was 100,000×.

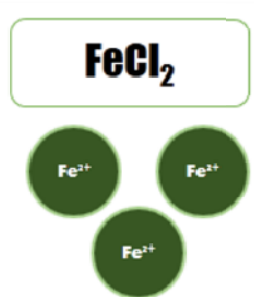

Source of $\mathrm{Fe}^{2+}$ ions
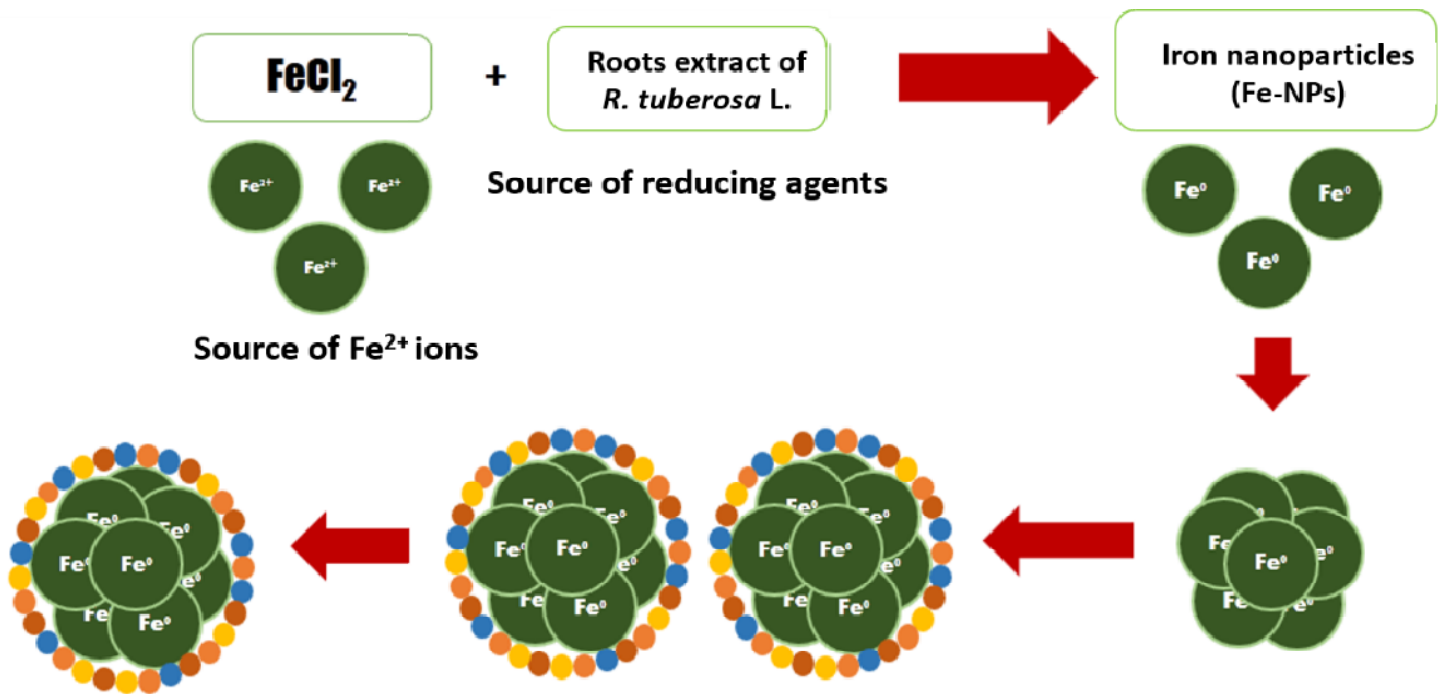

Fig.-4: Proposed Mechanism of Fe-NPs Formation with the Aid of Roots Extract of $R$. tuberosa L as Capping Agents. 
RASĀYAN J. Chem.

Vol. 13 | No. 1 |610 - 620| January - March | 2020

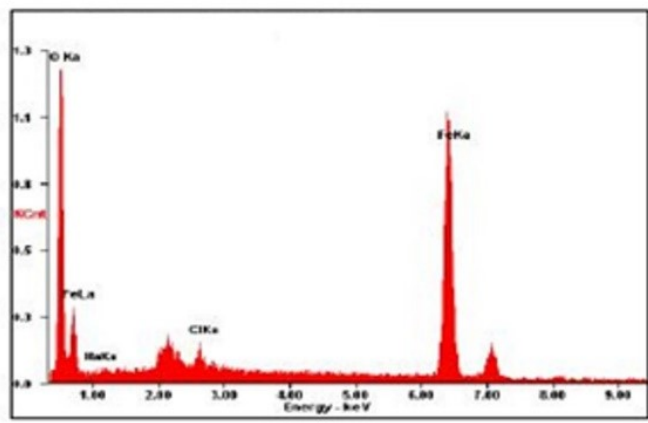

C

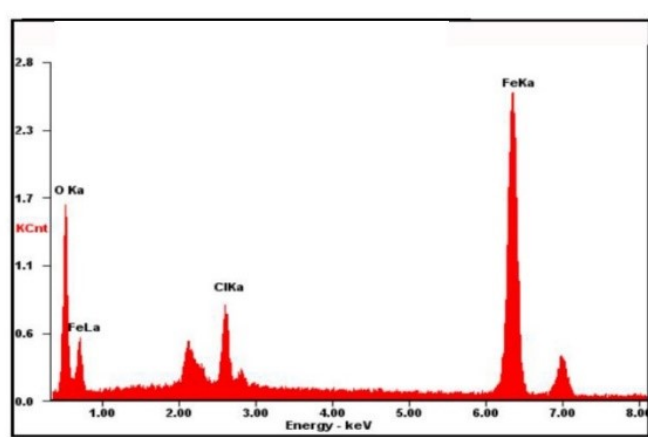

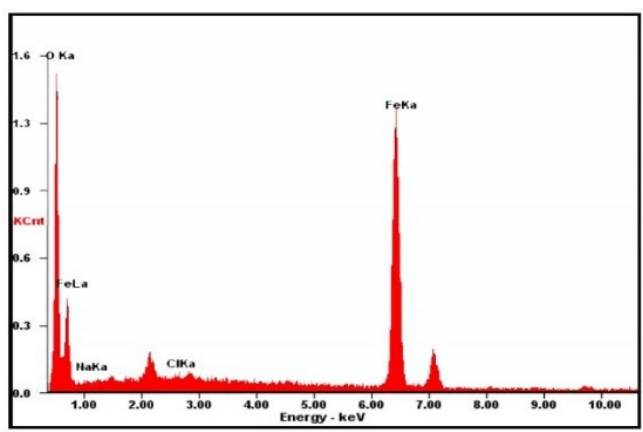

d

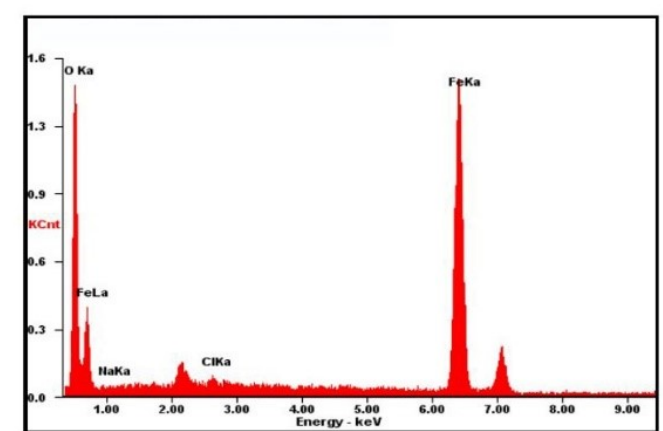

Fig.-5: EDS Spectra of the Fe-NPs at Different pH Conditions: (a) pH 3, (b) pH 5, (c) pH 7, and (d) pH 9.

The characteristics of Fe-NPs from FTIR spectra (wavenumbers $400-4000 \mathrm{~cm}^{-1}$ ) are provided in Fig.-6. The possible functional group responsible for the interaction between Fe-NPs and capping agent were assessed by conducting an FTIR analysis. The most distinct peaks shown for the Fe-NPs are labeled differently (A to G). The functional group corresponding to each label is listed in Table-2.

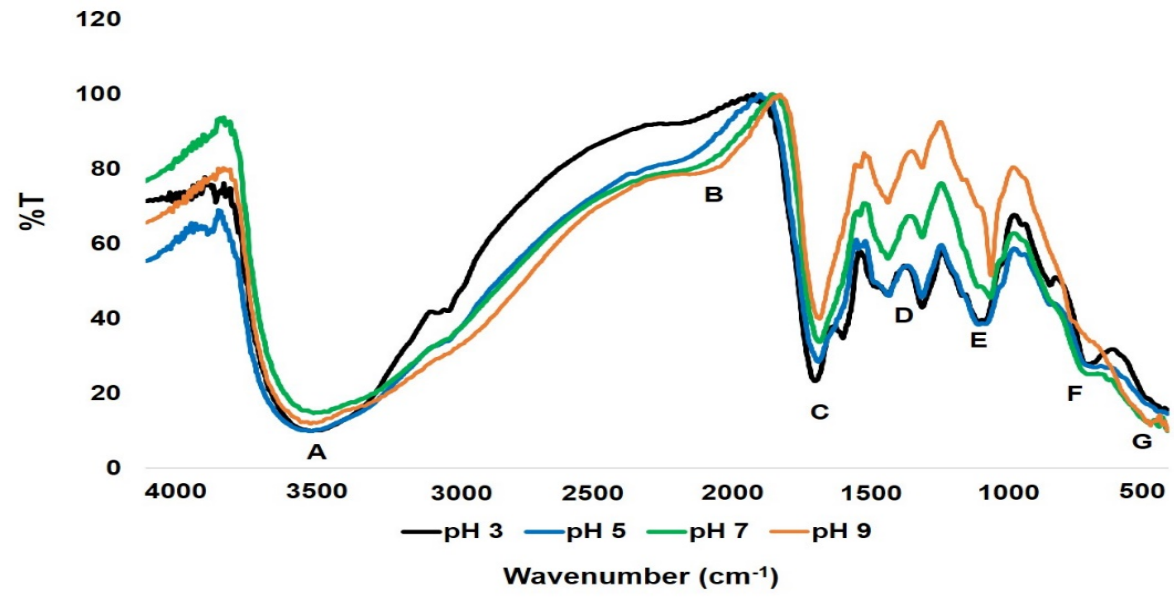

Fig.-6: The FTIR Spectra from Fe-NPs prepared at Different pH Conditions, pH 3, 5, 7, and 9. The Letters A-G indicated Prominent Absorption Peak, Functional Groups.

All synthesized nanoparticles at different $\mathrm{pH}$ have relatively similar peaks. The intense and broad absorption peak emerged at $3500-3400 \mathrm{~cm}^{-1}$, in region A, relates to the $\mathrm{O}-\mathrm{H}$ stretching vibrations of phenolic compounds and or/ carboxylic $\mathrm{acid}^{24}$, indicating that $\mathrm{O}-\mathrm{H}$ functional groups involved in the preparation of Fe-NPs. The phenolic compounds can act as a reductant for $\mathrm{Fe}^{2+}$ ions to $\mathrm{Fe}^{0}$, in addition, to be the capping agents on Fe-NPs surfaces. Peaks in region D $\left(1440-1420 \mathrm{~cm}^{-1}\right)$ relate to aromatic compounds, organics; and those compounds derivatives, such as alcohol, polyphenol, or organic acids, terpenoids, and proteins contained in the extracts. ${ }^{25,26}$ These suggest an interaction between hydroxyl groups or oxygen-containing groups from the $R$ tuberosa L. roots extract with the surface of Fe-NPs. The 
RASĀYAN J. Chem.

Vol. 13 | No. 1 |610 - 620| January - March | 2020

second intense absorption peak in region $\mathrm{C}$, found in $1650-1640 \mathrm{~cm}^{-1}$, corresponds to $\mathrm{C}=\mathrm{C}$ in alkene groups from non-saturated hydrocarbon compounds. Consequently, the FTIR spectra of Fe-NPs showed another prominent peak in region E $\left(1050-1030 \mathrm{~cm}^{-1}\right)$. This peak may link to heterocyclic compounds from plant extract, importantly from the carbonyl group. Another peak was detected in $\mathrm{F}$ area, in the range of $680-660 \mathrm{~cm}^{-1}$, by C-H stretching from aromatic compounds, and or/ alkenes. Finally, absorption bands at region $\mathrm{G}, 590-570 \mathrm{~cm}^{-1}$ belonged to Fe-O stretches, confirming the formation of Fe-NPs. This data was in agreement with results from a prior $s_{\text {tudy }}{ }^{23}$, that confirms the successful use of plant extracts to synthesize Fe-NPs, using FTIR analysis.

Table-2: The FTIR Absorption Peaks Assignment from Fig.-5

\begin{tabular}{c|c|c|c}
\hline Label & $\begin{array}{c}\text { Wavenumber } \\
\left(\mathrm{cm}^{-1}\right)\end{array}$ & Assignment & Compound indicated \\
\hline $\mathrm{A}$ & $3500-3400$ & $-\mathrm{OH}$ stretching & Polyphenols \\
\hline $\mathrm{B}$ & $1900-2000$ & $\mathrm{C}-\mathrm{H}$ stretching & Alkanes \\
\hline $\mathrm{C}$ & $1650-1640$ & $\mathrm{C}=\mathrm{C}$ stretching & Alkenes \\
\hline $\mathrm{D}$ & $1440-1420$ & $\begin{array}{c}\mathrm{CH} \text { bending } \\
\mathrm{C}-\mathrm{C} \text { stretching }\end{array}$ & Alkenes \\
& & $\mathrm{C}-\mathrm{O}-\mathrm{C}$ stretching & Carbonyl compounds \\
\hline $\mathrm{E}$ & $1050-1030$ & $\mathrm{C}-\mathrm{H}$ bending & Alkenes, Aromatics \\
\hline $\mathrm{F}$ & $680-660$ & $\mathrm{Fe}-\mathrm{O}$ stretching & $\mathrm{Fe}(0)$ \\
\hline $\mathrm{G}$ & $590-570$ & &
\end{tabular}

The antibacterial activity of Fe-NPs prepared from $R$. tuberosa L root extracts was examined against pathogenic bacteria, $S$. aureus and $E$. coli using well diffusion method. The zone of inhibitions formation at different pathogenic bacteria at different $\mathrm{pH}$ values is shown in Fig. -7 , and the zone of inhibition from positive controls (ampicillin and chloramphenicol) is displayed in Fig.-8. The Fe-NPs used were in different concentrations, 1.5 to $100 \%(\mathrm{v} / \mathrm{v})$, however, the $100 \%$ concentration resulted in the highest inhibition against both bacteria. Therefore, the zones of inhibition in mm diameter around each well with Fe-NPs solution listed in Table-3 are at $100 \%$ concentration. The synthesized Fe-NPs have shown prominent anti-bacterial activities against $S$. aureus and E. coli. Nonetheless, anti-bacterial studies elucidate that $S$. aureus, gram-positive bacteria, is more sensitive to Fe-NPs, in comparison with $E$. coli, gram-negative bacteria. Similar trends were observed in the anti-microbial capacity of ampicillin and chloramphenicol, which resulted in the higher numbers in inhibition zones against $S$. aureus, rather than E. coli (Fig.-9).

It is known that gram-negative bacteria are less sensitive to the action of an anti-microbial agent, compared to gram-positive bacteria. Because there is a monolayer cell wall in gram-positive bacteria, that has lower lipid content, allowing any compounds from outside their cell wall entering the cell. On the other hand, there is a three-layer cell wall structure in gram-negative bacteria, comprising of outer, lipopolysaccharide, and peptidoglycan layers with higher lipid content, and, hence, it is quite tough to intercept their cell walls. ${ }^{27,28}$

Table-3: Zone of Inhibition of Fe-NPs prepared From $R$ tuberosa $\mathrm{L}$. Root Extract at Different $\mathrm{Ph}$

\begin{tabular}{c|c|c}
\hline \multirow{2}{*}{$\mathrm{pH}$} & \multicolumn{2}{|c}{ Zone of Inhibition against } \\
\cline { 2 - 3 } & $\begin{array}{c}\text { S. aureus } \\
(\mathrm{mm})\end{array}$ & $\begin{array}{c}\text { E. coli } \\
(\mathrm{mm})\end{array}$ \\
\hline 3 & 16.70 & 13.40 \\
\hline 5 & 15.20 & 11.85 \\
\hline 7 & 10.80 & 9.20 \\
9 & 7.20 & 7.40 \\
\hline Amphicillin & 25.70 & 25.40 \\
Chloramphenicol & 30.20 & 29.85 \\
\hline
\end{tabular}

616 
RASĀYAN J. Chem.

Vol. 13 | No. 1 |610 - 620| January - March | 2020
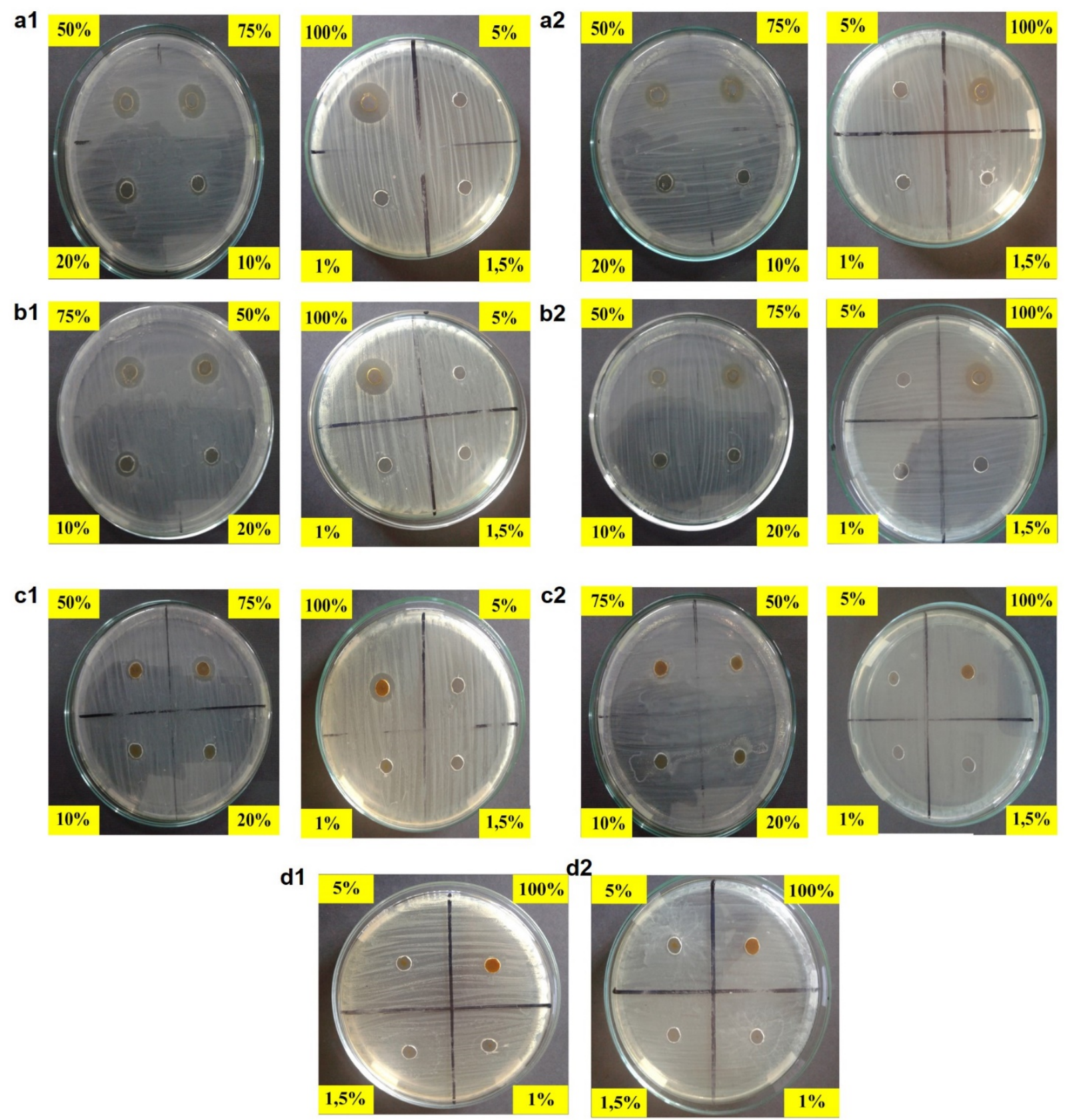

Fig.-7: Results From Antimicrobial Assay, Showing Clear Inhibition Zones of Fe-NPs at Different Concentrations (v/v), prepared From Different pH: (a) pH 3; (b) $\mathrm{pH} 5$; (c) $\mathrm{pH} 7$; and (d) $\mathrm{pH}$ 9. Label Number 1 is the Antimicrobial Test against $S$. aureus, and Label Number 2 is against $E$. coli.

It is interesting that in the antibacterial test, the lowest $\mathrm{pH}$ used $(\mathrm{pH} 3)$ for the preparation of Fe-NPs, resulted in the maximum inhibition zones for both bacteria, S. aureus and E. coli. This suggests that the antibacterial activity of metal nanoparticles is influenced by $\mathrm{pH}$ conditions. The toxicity of nanoparticles depends on a combination of several factors such as temperature, precursor concentration, type of bacteria used for testing, and $\mathrm{pH}$ conditions. ${ }^{17,18}$ In this study, results from SEM images indicated that agglomeration and bigger size particles on Fe-NPs occurred to the lowest $\mathrm{pH}(\mathrm{pH} 3)$, and, thus, resulted in the highest toxicity to the bacteria. The Fe-NPs showed efficient antibacterial property at $\mathrm{pH} 3$, compared to other $\mathrm{pH}$ conditions attributable to their large surface area, which offers better interaction with bacteria. 
RASĀYAN J. Chem.

Vol. 13 | No. 1 |610 - 620| January - March | 2020

Another possible explanation is that the compounds acting as a coating molecule or capping agent also influenced the antimicrobial activity of the resulted Fe-NPs. The LC-MS results from the extracts used showed that the extracts contained mostly flavonoid compounds, including sorbifolin, cirsimaritin, cirsimarin, and cirsiliol 4'-glucoside. ${ }^{15}$ Based on the $\mathrm{pKa}$ values of each compound, there are 3 compounds (sorbifolin, cirsimaritin, and cirsiliol 4'-glucoside) with a pKa value greater than acidic $\mathrm{pH}$ conditions, therefore, the ionization of the three compounds is favorable, allowing those compounds to interact easily with the membrane on cell wall bacteria.
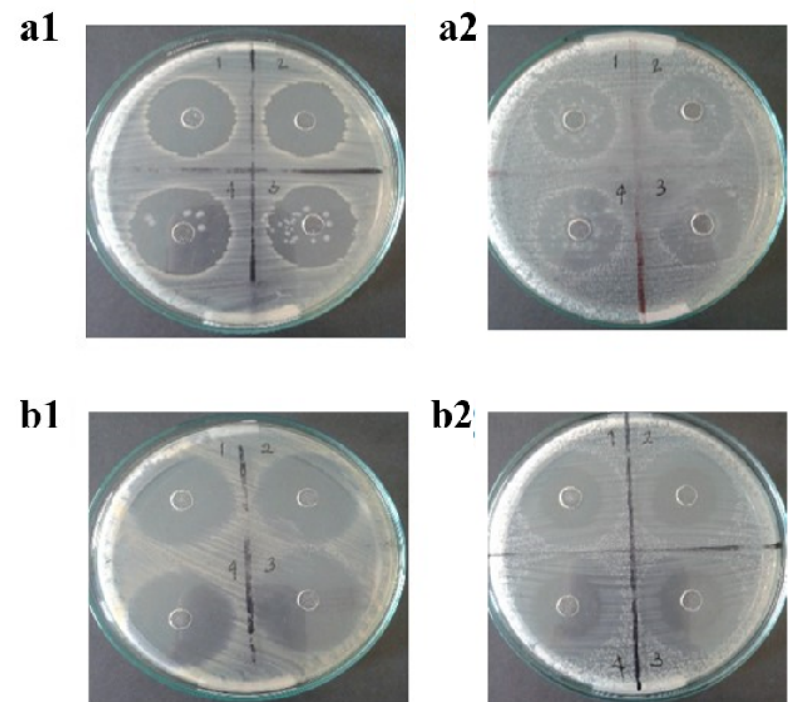

Fig.-8: Results from Antimicrobial Assay, Showing Clear Inhibition Zones of From; (a) Ampicillin; (b) Chloramphenicol. Label Number 1 is Antimicrobial Test against $S$. aureus, and Label Number 2 is against E. coli.

However, in alkaline conditions, there is only one compound (cirsimarin) having pKa value almost the same with the $\mathrm{pH}$, thus, reducing its ionization capacity, and as a result, does not interact strongly with the bacteria. These may cause antimicrobial activity is more significant in acidic conditions than in alkaline conditions.

Overall, the proposed mechanism of action of Fe-NPs as an antibacterial agent is the nanoparticles attached to the membrane or cell wall, then also infiltrated inside the bacteria. The bacterial membrane comprises of sulfur-containing proteins; and the iron nanoparticles react with these proteins in the cell, as well as with the DNA. Once Fe-NPs enter the bacterial cell, they block cellular channels and as a result causing membrane damages, or inhibit the intake of the nutrients and cell mobility. It is, consequently, resulted in cell lysis (Fig.-9).
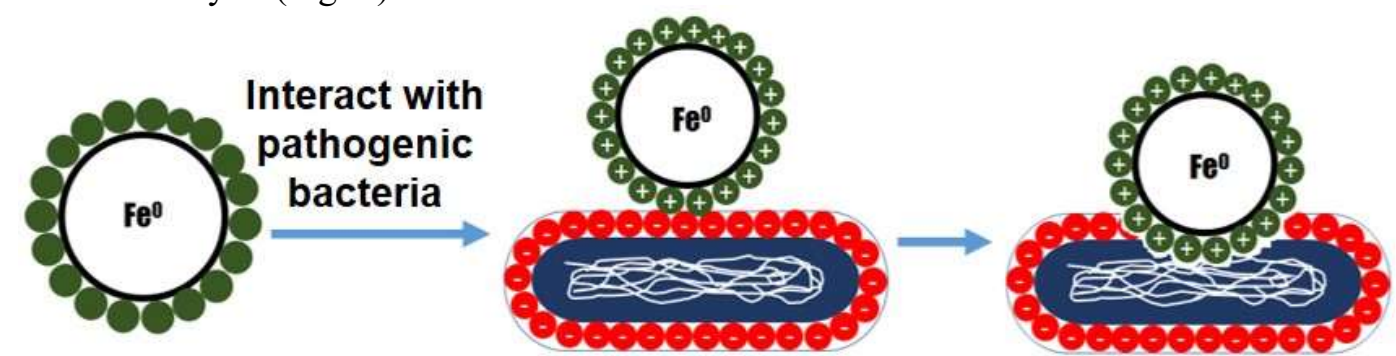

Cell membrane damage

Fig.-9: Proposed Mechanism of Action of Fe-NPs acting As An Antibacterial Agent.

\section{CONCLUSION}

The Fe-NPs have been successfully prepared from roots extract of $R$. tuberosa L., using an inexpensive, effective, and environmentally friendly technique. The UV-vis spectrophotometry, SEM-EDS, and FTIR 
RASĀYAN J. Chem.

Vol. 13 | No. 1 |610 - 620| January - March | 2020

spectroscopy analyses suggest the reduction of $\mathrm{Fe}(\mathrm{II})$ to $\mathrm{Fe}(0)$. In this investigation, $R$. tuberosa L. roots extract was determined to act as a reducing agent and to form capping layers around the nanoparticles. The particle sizes of Fe-NPs were dependent on $\mathrm{pH}$ condition, $\mathrm{pH} 9$ contributed to the most homogenous surface and the smallest size. FTIR spectra result demonstrated that carboxylate and hydroxyl groups of the extracts interacted with the iron nanoparticles and lead surface stabilization. The inhibition zones shown in the antibacterial screening test indicating that the Fe-NPs prepared in the current work has the effective antibacterial activity against pathogenic $S$. aureus and $E$. coli. In contrast, $\mathrm{pH} 3$ resulted in the highest inhibition zones of Fe-NPs. The Fe-NPs that prepared biologically could be of convenient use in they for their proficient antibacterial activities.

\section{REFERENCES}

1. X. Zhang, S. Lin, Z. Chen, M. Megharaj, R. Naidu, Water Research 45(11), 3481(2011), DOI: 10.1016/j.watres.2011.04.010.

2. T. Shahwan, S. Abu Sirriah, M. Nairat, E. Boyaci, A.E. Eroğlu, T.B. Scott, K.R. Hallam, Chemical Engineering Journal, 172(1), 258(2011), DOI: 10.1016/j.cej.2011.05.103.

3. M.H. Jang, M. Lim, Y.S Hwang, Environmental Analysis Health and Toxicology, 29, 2014(e2014022), DOI: 10.5620/eht.e2014022.

4. K.M. Kumar, B.K. Mandal, K.S. Kumar, P.S. Reddy, B. Sreedhar, Spectrochimica Acta Part A: Molecular and Biomolecular Spectroscopy, 102, 128(2013), DOI: 10.1016/j.saa.2012.10.015.

5. L. Huang, X. Weng, X. Chen, M. Megharaj, R. Naidu, Spectrochima Acta Part A: Molecular and Biomolecular Spectroscopy, 117, 801(2014), DOI: 10.1016/j.saa.2013.09.054

6. F. Zhu, S. Ma, T. Liu, X. Deng, Journal of Cleaner Production, 174, 184 (2018), DOI: 10.1016/j.jclepro.2017.10.302.

7. S. Machado, S.L. Pinto, J.P. Grosso, H.P.A. Nouws, J.T. Albergaria, C. Delerue-Matos, Science of the Total Environment, 445-446, 1(2013), DOI:10.1016/j.scitotenv.2012.12.033.

8. T. Wang, X. Jin, Z. Chen, M. Megharaj, R. Naidu, Science of the Total Environment, 466-467, 210(2014), DOI: 10.1016/j.scitotenv.2013.07.022.

9. M. Gopalakrishnan, A. Sheenu, B. Varghese, J. Dharani, S. Saranya, Rasayan Journal of Chemistry, 12(3), 1072(2019), DOI: 10.31788/RJC.2019.1235136.

10. G.M. Srirangam, K.P. Rao, Rasayan Journal of Chemistry, 10(1), 46(2017), DOI: /10.7324/RJC.2017.1011548.

11. P. Vijaya Kumar, S. Mary Jelastin Kala, K S. Prakash, Rasayan Journal of Chemistry, 11(4), 1544(2018), DOI: 10.31788/RJC.2018.1144044

12. A.R. Ahmad, B. Elya, A. Mun'im, Pharmacognosy Journal, 9(5), 607(2017), DOI: 10.5530/pj.2017.5.96.

13. M.A Alam, N. Subhan, M.A. Awal, M.S. Alam, L. Nahar, S.D. Sarker, Pharmaceutical Biology, 47, 209(2009), DOI:10.1080/13880200802434575.

14. A. Safitri, A. Roosdiana, I. Rosyada, C. A. Evindasari, Z. Muzayyana, R. Rachmawanti, IOP Conference Series: Materials Science and Engineering, 509, 012017(2019), DOI:10.1088/1757899X/509/1/012017.

15. M. Ramadhan, A. Sabarudin, A. Safitri, IOP Conference Series: Earth and Environmental Science, 239, 012028(2019), DOI:10.1088/1755-1315/239/1/012028.

16. M.N. Samy, S. Sugimoto, K. Matsunami, H. Otsuka, M.S. Kamel, International Journal of Pharmacognosy, 2, 270(2015), DOI:10.13040/IJPSR.0975-8232.IJP.2(6).270-79.

17. M. Balouiri, M. Sadiki, S.K. Ibn Souda, Journal of Pharmaceutical Analysis, 6(2), 71(2016), DOI: /10.1016/j.jpha.2015.11.005.

18. T.Y. Suman, S.R. Rajasree, R. Ramkumar, C. Rajthilak, P. Perumal, Spectrochimica Acta Part A: Molecular and Biomolecular Spectroscopy, 118, 11(2014), DOI: 10.1016/j.saa.2013.08.066.

19. S.L. Smitha, D. Philip, K.G. Gopchandran, Spectrochimica Acta Part A: Molecular and Biomolecular Spectroscopy, 74(3), 735(2009), DOI: 10.1016/j.saa.2009.08.007.

20. M.R. Maurya, V. Toutam, The Journal of Physical Chemistry, 120(34), 19316(2016), DOI: 10.1021/acs.jpcc.6b05847. 
RASĀYAN J. Chem.

Vol. 13 | No. 1 |610 - 620| January - March | 2020

21. F. C. Nalle, R. Wahid, I. O. Wulandari, A. Sabarudin, Rasayan Journal of Chemistry, 12, 14(2019), DOI:10.31788/RJC.2019.1214082.

22. A. Saif, T. Tahir, T. Asim, Y. Chen, Nanomaterials (Basel), 6(11), 205(2016), DOI: 10.3390/nano6110205.

23. M. Fazlzadeh, K. Rahmani, A. Zarei, H. Abdoallahzadeh, F. Nasiri, R. Khosravi, Advanced Powder Technology, 28(1), 122(2017), DOI: 10.1016/j.apt.2016.09.003.

24. F.D. Grasel, M.F. Ferrão, C.R. Wolf, Spectrochimica Acta Part A: Molecular and Biomolecular Spectroscopy, 153, 94(2016), DOI: 10.1016/j.saa.2015.08.020.

25. E.A. Vargas-León, L. Díaz-Batalla, L. González-Cruz, A. Bernardino-Nicanor, J. Castro-Rosa, R. Reynoso-Camacho, C.A. Gómez-Aldapa, C. A., Industrial Crops and Products, 116, 201(2018), DOI: $10.1016 /$ j.indcrop.2018.02.044.

26. H. Xin, X. Yang, X. Liu, X. Tang, L. Weng, Y. Han, Journal of Nanotechnology, 2016, 4059591(2016), DOI: 10.1155/2016/4059591.

27. T.J. Silhavy, D. Kahne, S. Walker, Cold Spring Harbor Perspectives in Biology, 2(5), a00414(2010), DOI: 10.1101/cshperspect.a000414.

28. M. Jankute, J.A. Cox, J. Harrison, G.S. Besra, Annual Review of Microbiology, 69, 405(2015), DOI:10.1146/annurev-micro-091014-104121.

[RJC-5511/2019] 